\title{
Dysgermgerminoma in a 14 year old girl: a case report
}

\section{N. Kurude*, Sukanya Thorat}

Department of Obstetrics and Gynecology, Grant Medical College and Sir Jamshedjee Jeejeebhoy Group of Hospitals, Mumbai, Maharashtra, India

Received: 27 December 2016

Revised: 07 January 2017

Accepted: 31 January 2017

\section{*Correspondence:}

Dr. V. N. Kurude,

E-mail: drvnkurude@gmail.com

Copyright: () the author(s), publisher and licensee Medip Academy. This is an open-access article distributed under the terms of the Creative Commons Attribution Non-Commercial License, which permits unrestricted non-commercial use, distribution, and reproduction in any medium, provided the original work is properly cited.

\begin{abstract}
An accurate diagnosis of ovarian dysgerminoma is crucial as, as its management differs from other ovarian tumours. We report a case of ovarian dyegerminoma in a 14 year old girl who presented with abdominal distention. Examination revealed a huge intra-abdominal mass causing displacement of bowel loops laterally. On ultrasound, a solid heterogeneously hyperechoic lesion of size $18 \times 9.4 \mathrm{~cm}$ with few cystic and necrotic areas within most likely, left adnexa reaching upto the umbilicus and shows vascularity within both ovaries not seen separately from the lesion. On CT (A+P), a heterogenous hypodense polycystic mass of size $8.5 \times 1.4 \times 16.7$ with multiple irregular hypodensities seen in the lower abdomen and pelvis. The mass was removed after laparotomy under general anaesthesia. Finally, the diagnosis of ovarian germ cell tumor (Dysgerminoma was made. Present case presented with marked abdominal distention, without any loss of weight, appetite or any menstrual problem. Such a presentation may be unusual for such a large malignant ovarian mass.
\end{abstract}

Keywords: Dysgerminoma, Germinoma, Ovarian neoplasms, Seminoma

\section{INTRODUCTION}

Ovarian germ cell tumours are derived from primordial germ cells of the ovary. They may be benign or malignant and comprise about $30 \%$ of ovarian neoplasms and $3 \%$ of all malignant ovarian neoplasms. ${ }^{1}$ They arise in young women between 10 and 30 years of age. These tumors grow rapidly, and present with a large ovarian mass with early stage disease. Malignant GCT's are being classified into subgroups, the most common of it is dysgerminoma. It is a female counterpart of testicular seminomas in males. Such cases usually present with abdominal distention, dull pain. ${ }^{2}$

\section{CASE REPORT}

A 14 year old unmarried female presented in surgery OPD with abdominal mass since 5-6 months, along with pain in abdomen. Patient has not shown to any doctor previously. She was referred from surgery OPD to Obstetrics and Gynecology OPD. Patient had no any history of irregular menses or change in bowel/bladder habits or any weight loss. Her menstrual cycles were regular. On clinical examination, a 24 to 26 weeks size hard mass arising from the pelvis. On ultrasound, a solid heterogeneously hyperehoic lesion of size 18 x $9.4 \mathrm{~cm}$ with few cystic and necrotic areas within, most likely from left adnexa reaching upto the umbilicus and shows vascularity within both ovaries not seen separately from the lesion. On $\mathrm{CT}(\mathrm{A}+\mathrm{P})$, a heterogenous hypodense polycystic mass of size $8.5 \times 1.4$ x 16.7 with multiple irregular hypodensities. Large solid cystic mass in the lower abdomen and pelvis suggestive of ovarian neoplasm. Patient was planned for exploratory laparotomy with frozen section. Patient underwent an exploratory laparotomy with left sided ovariectomy with left sided salpingectomy. Examination of the surgical 
specimen revealed the ovarian mass of size $8.5 \times 1.4 \times 16.7$ $\mathrm{cm}$. Specimen was immedieatly sent for frozen section which was suggestive of left ovary dysgerminoma. Microscopic examination revealed typical characterstics of ovarian dysgerminoma. Neoplastic cells were dispersed in sheets and cords separated by scanty fibrous stroma. The cytoplasm contained glycogen, thus the cells were PAS. Final diagnosis of our case was left ovary dysgerminoma. Microscopic examination of peritoneal fluid was suggestive of clusters of mesothelial cells under background of neutrophilic infiltration anfproteinaceousmaterial. Patient had an uncomplicated postoperative course and was asked to follow up for chemotherapy.

\section{DISCUSSION}

A dysgerminoma is an ovarian tumor which is composed of primitive undifferentiated germ cells that arise from the primordial germ cells of the ovary. They are found usually in adolescents and young adults. Approximately $60 \%$ of the cases are diagnosed in patient younger than 20. Of all these ovarian lesions, $97 \%$ are benign lesions, the remaining $3 \%$ are malignant. ${ }^{1}$ The most commonly occurring GCT is dysgerminoma that accounts for almost $2 \%$ of all ovarian cancers. Such tumors usually present as a unilateral mass, have rapid growth, can occur during pregnancy and can predispose to rupture and torsion with associated acute changes in approximately 5-10\%.

Dysgerminomas presenting as stage I cancer, can be treated by surgical resection alone with a unilateral salpingo-oophorectomy. ${ }^{2}$ This is preferred treatment modality when attempting to preserve fertility; however, follow-up care, with serial pelvic examinations and tumor markers [i.e. beta-human chorionic gonadotropin (betahCG), alpha-fetoprotein (AFP), lactate dehydrogenase $(\mathrm{LDH})]$ is a must if resection is the only treatment modality.

Radiation therapy has also been administered to patients with stage I-III tumors, with excellent response rates overall. For stage Ib-4 ovarian dysgerminomas, adjuvant therapy is usually reserved. ${ }^{3}$ Platinum-based chemotherapy has high success rates as it is well tolerated, as well as avoiding long-term complications from radiation, including sterility and early menopause. ${ }^{4}$

\section{CONCLUSION}

Dysgerminoma represents a distinct category, given its exquisite radio- and chemosensitivity. As many as twothirds of patients with dysgerminoma present with stage I at diagnosis. In the past, most women with dysgerminoma received postoperative radiotherapy. Given the risks of secondary malignancies, gonadal dysfunction, and sterility associated with pelvic radiotherapy, an alternative option for patients at low risk is postsurgical clinical surveillance. With this approach, $80 \%$ to $85 \%$ of patients with stage IA dysgerminoma are cured, but careful follow-up is required to ensure early detection of recurrences in those 15 to $25 \%$ of patients whose disease will recur. Given dysgerminoma's exquisite chemosensitivity, virtually all patients can be salvaged at the time of recurrence, if early detection has been accomplished.

\section{Funding: No funding sources}

Conflict of interest: None declared

Ethical approval: Not required

\section{REFERENCES}

1. Cancer survival by stage at diagnosis for England (experimental statistics): Adults diagnosed 2012, 2013 and 2014 and followed up to 2015; Office for National Statistics (ONS).

2. Shamim M: Successful pregnancy outcome after fertility-sparing surgery and chemotherapy for dysgerminoma. J Pak Med Assoc. 2010,60:779-81.

3. Lazebnik N, Balog A, Bennett S, Redline R, Liu J. Ovarian dysgerminoma: a challenging clinical and sonographic diagnosis. J Ultrasound Med. 2009;28:1409-15.

4. Ovarian cancer- the recognition and initial management of ovarian cancer. NICE Clinical Guideline; 2011.

Cite this article as: Kurude VN, Thorat $\mathrm{S}$.

Dysgermgerminoma in a 14 year old girl: a case report. Int J Reprod Contracept Obstet Gynecol 2017;6:1149-50. 